Laboratorio de Arte, 7-1994 http://dx.doi.org/10.12795/LA.1994.i07.12

\title{
STUDIO 52: UN EJEMPLO DE MODERNIDAD ARQUITECTÓNICA EN CÓRDOBA
}

\author{
POR EMILIA MORALES CAN̄ADAS
}

\begin{abstract}
En este trabajo se pretende trazar una panorámica de las incidencias que las vanguardias han tenido en la capital cordobesa, tomando como referencia un establecimiento fotográfico que agrupa no sólo un estudio y una zona de ventas, sino también una sala de exposiciones, suponiendo por tanto un ámbito propiciador de experiencias constructivas y plásticas que han variado desde su aparición en los años cincuenta hasta hoy, y cuyo testimonio más claro lo ofrecen las dos ubicaciones que ha tenido y que aquí analizamos bajo el punto de vista arquitectónico principalmente.
\end{abstract}

In this work it's sitended to lay out a view of the incidences that the vanguardism had on the city of Cordoba, taking as reference a photographic establishment that gathers not only a study and a comercial zone, but also an exposition hall, therefore resolving a propitious scope of constructive and plastic experiences which have varied since their first appearance on the fifties' until today, and which clearest testimony is offered by the locations it had, and that we have analyze under the arquitectonic point of view mainly.

Desde un punto de vista actual, cuando el término "arte" se aplica a disciplinas tan heterogéneas que lo han vaciado de un contenido preciso, no nos sorprenden en absoluto la hibridación de géneros y la aparición de obras globalizadoras en las que participan de igual modo la obra plástica, junto con la arquitectura y el diseño. Sin embargo, ese fenómeno que ahora resulta casi necesario en la búsqueda de nuevas experiencias, no debe confundirnos al analizar las actuaciones que arquitectos y artistas llevaron a cabo en otros momentos históricos como respuesta a un ambiente y unas inquietudes creativas determinadas. Con este distanciamiento podremos valorar mejor la estética de los años cincuenta, aplicable a todos los campos, hundiendo sus raíces en la revolucionaria escuela de la Bauhaus. Las propuestas de la escuela alemana fueron una bocanada de modernidad que se truncó prematuramente, y aunque sus enseñanzas han planeado sobre realizaciones posteriores, es precisamente a mediados de siglo cuando se recupera el interés por el diseño industrial, tomando de aquélla el gusto por lo funcional y por la comunión de disciplinas. 
Centrándonos en primer lugar en la arquitectura, y pese a la validez internacional de los presupuestos referidos, no podemos olvidar las circunstancias particulares que determinaron el caso español. Mucho se ha dicho y escrito ya acerca del aislamiento que supuso para España el final de su guerra civil y su consecuente falta de conexión con las vanguardias del exterior. No se recibía una información eficaz en el terreno arquitectónico, ya que las relaciones establecidas con Italia y Alemania traían sus connotaciones ideológicas plasmadas en la arquitectura fascista y nazi. Las revistas, medio de difusión esencial, llegaban con retraso. La evolución, haciendo hincapié en Andalucia, se produce partiendo del Historicismo y Eclecticismo, pasando por el Regionalismo, adoptando elementos formales aislados -no el concepto- del Racionalismo, para volver a un tradicionalismo antimoderno. '

A esta situación particular hay que añadir el receso que en el resto del mundo sufrió el desarrollo del Movimiento Moderno iniciado en los últimos años veinte, interrumpido por la Guerra Mundial y retrasado hasta una década después, trasladándose entonces el centro originador de influencias a Estados Unidos.

Desde principios de la década de los cuarenta la Revista Nacional de Arquitectura es en España el órgano oficial de expresión, y en ella se detecta hacia 1950, cuando hace su eclosión la llamada segunda generación de postguerra ${ }^{2}$, ese ambiente confuso en el que se intentaba abrir paso una arquitectura diferente de la establecida. Sus páginas se hacen eco de la coexistencia de ciertas costumbres constructivas y decorativas de claro signo ecléctico y desfasado, con una voluntad de renovación apoyada en puntuales avances tecnológicos -la publicidad demuestra el surgimiento de industrias afines a la arquitectura, muy especializadas- y haciéndose eco de las realizaciones tanto europeas como americanas, así como de las publicaciones. El modelo estético reflejado en la revista es el Funcionalismo: en el plano teórico se hace crítica enardecida a favor de la depuración y en contra de todo detalle "superfluo" que no forme parte directamente de la construcción en sí y de su función.

En el plano práctico, un cierto sentimiento de optimismo en el terreno económico será decisivo para la asimilación de nuevos lenguajes arquitectónicos, aplicados por una parte a las labores de reconstrucción, colonización agraria, planeamiento urbanístico y cnstrucción de viviendas sociales, y por otra parte a encargos privados beneficiados de incipientes acumulaciones de capital. Se retoman las directrices racionalistas emprendidas en España por GATEPAC en los años treinta y su traducción formal consiste en el abandono individual, por parte de los arquitectos, del historicismo de sus primeras obras y su acercamiento a la estética

1. Ver MOSQUERA ADELL, E.: La Vanguardia imposible: quince visiones de arquitectura contemporánea andaluza. Sevilla, 1990.

2. Pertenecen a esta generación, entre otros, Bohigas, Carvajal, Corrales, Cubillo, García de Paredes, La-Hoz, Martorell, MIlá, Molezun, Ortiz Echagüe, Romany, Sáenz de Oiza, Sierra, etc. (Ver FLORES, C.: Arquiteciura española contemporánea. Bilbao, 1961, p.248) 
del desarrollismo industrial dentro de la idea de progreso que dominaba la mentalidad del momento. Se trata de dar desde el Estado un aire de aperturismo, para el que se utilizan otros aspectos también, como las exposiciones de pintura contemporánea -recordemos la Primera Bienal Hispanoamericana de Arte, la Exposición Internacional de Arte Abstracto de Santander y otros acontecimientos de los primeros años cincuenta-.

En capitales de provincia de interior, como es el caso de Córdoba, sólo muy lentamente podían asimilarse las novedades artísticas, a diferencia de las arquitectónicas. Claro ejemplo de este ambiente nos lo ofrece el testimonio de la Primera Exposición de Arte Contemporáneo que tuvo lugar en 1953, coincidiendo con el centenario del Círculo de la Amistad, en la que Fernando Carbonell como promotor contó primero con el asesoramiento de Antonio Povedano, luego unido al también pintor Carlos Pascual de Lara. El arquitecto Rafael de La-Hoz se encargó de acondicionar la sala, que fue pintada de negro humo, para el montaje de lo que resultó ser una exposición polémica e incomprendida por el público local. Parece casi obligado que surgiera esta espontánea colaboración entre los diversos personajes comprometidos con la modernidad, iniciando así un nuevo modo de ver y de entender la creación de manera colectiva, cuya mejor proyección sería el "Equipo 57". 3

\section{RAFAEL DE LA-HOZ}

Rafael de La-Hoz pertenece, como se ha visto, al grupo de arquitectos de la segunda generación de postguerra, que en los años cincuenta iniciaron su andadura profesional impulsados por el afán de renovación. Desde sus primeras obras queda bien demostrado esto ya que, a diferencia de otros, no pasa previamente por el Historicismo, y a él se atribuye justamente la introducción del Estilo Internacional en Córdoba. Formado en la Escuela de Arquitectura de Madrid y titulado al mismo tiempo que García de Paredes, reciben en Córdoba el encargo de la Cámara de Comercio, cuya sede realizarán juntos entre 1951 y 1953. Está considerada esta obra como una de las dos iniciadoras del Movimiento Moderno en España -la otra es la Casa Ugalde en Caldetas (Barcelona) de Coderch y Valls-. Pero en lo que nos atañe aquí, tenemos que observar cómo su trazado, el contraste de la linealidad de la fachada con el interior, mucho más cargado de sinuosidades organicistas, coinciden con el concepto que aplica al diseño de la tienda "Studio".

Podríamos establecer tipologías dentro de la arquitectura de Rafael de La-Hoz, no sólo a través de su intensa trayectoria, sino incluso ciñéndonos a esta su primera época cordobesa. Si atendemos al tipo de encargo, nos sorprende la versatilidad

3. Sobre el "Equipo 57" véanse: PÉREZ VILLÉN, A.L.: Equipo 57. Córdoba, 1987; A.A.V.V.: Equipo 57 (Catálogo). Madrid, 1993. 
con que este arquitecto ha sabido conjugar función y forma sin perder nunca sus horizontes de hacer más agradable la vida al hombre dentro de un edificio coherente. De este modo se nos presentan sus bloques de viviendas que se adaptan a solares urbanos con atractivas soluciones, otros de vivienda social -interesantes aportaciones al denominado "bloque en $\mathrm{H}^{\text {"- }}$ grandes complejos como el Colegio Mayor Aquinas (1953), en colaboración con García de Paredes y que les valió el Premio Nacional de Arquitectura en 1956. Su vertiente más creativa, no obstante, se pone de manifiesto en los proyectos de chalets y tiendas, donde se conjugan los más audaces experimentos constructivos y estructurales con el esmerado diseño de interiores. Chalets como "La Cabaña" (1954), "Canals" (1955), "La Barraca" (1957), "El Bosque" (1951), "Pericet" (1958) y otros posteriores, son un alarde de adaptación al medio, aprovechando los desniveles del terreno y tomando en consideración los rigores climáticos de la zona -en su mayoría afueras de Córdoba- para la mejor disposición de cerramientos, amplios vanos y cubiertas en voladizo. Su interior responde generalmente a un esquema distributivo que agrupa las estancias de habitación diurna por un lado y los dormitorios, frecuentemente a lineados en un eje longitudinal, en el otro flanco -el chalet "Canals", así como "El Bosque" son ejemplos originales donde este eje destaca en planta y alzado como un airoso cuerpo independiente adosado por su extremo-.

Uno de los rasgos característicos del estilo de estas obras es la diafanidad conseguida por medio de grandes lunas, algo que encuentra su paralelismo claro en las fachadas de las tiendas diseñadas por Rafael de La-Hoz en estos años. Nos trasladamos ahora de la periferia al centro neurálgico de Córdoba. En el entramado de la Avenida del Gran Capitán, Cruz Conde, Gondomar y Avenida del Generalísimo, hoy Ronda de los Tejares, zona que ha sido múltiples veces intervenida urbanísticamente, se efectuaban entonces, como ahora, las más radicales innovaciones de la ciudad. Allí se ubicaba la cafetería "Dunia", punto de encuentro de los más modernos, y muy cerca se instaló la tienda "Vogue" (1951), primera obra de Rafael de La-Hoz. Más que arquitectura habría que hablar de integración del diseño arquitectónico con el diseño "industrial", 4 en una suerte de interiorismo bien resuelto.

No estamos hablando de un hecho aislado, sino de una nueva aplicación de la arquitectura a nivel nacional e internacional. Aparte la existencia de alguna que otra empresa instaladora de comercios, desde la Revista Nacional de Arquitectura se propugna la conveniencia de encargar la construcción de los locales comerciales, en su incipiente pujanza, a arqitectos capacitados para conseguir resultados más

4. En la Revista Nacional de Arquitectura, número 131, correspondiente a noviembre de 1952 se reproducen imágenes tanto de la tienda "Vogue" como de la mesa de despacho que diseñó Rafael de La-Hoz por encargo de un ingeniero de la Diputación no especificado, basándose en la silla que el mismo poseía, de Carlo de Carli. (pp. 48, 49, 50). 
efectivos. Se empiezan a valorar los elementos que pueden funcionar como reclamos si se cuidan debidamente, y es así como en 1952 se dedica un completo artículo a las fachadas de tiendas, consideradas como auténticos carteles publicitarios, y estudiando de ellas tanto su disposición respecto a la calle como el escaparatismo, la rotulación, la disposición de los objetos de acuerdo con los ángulos de visión humana, la iluminación de los mismos, etc. A partir de entonces, conscientes de la importancia de este tipo de trabajos -y de su puesto en la economía nacional, seguramente- se dedican habitualmente varias páginas de la revista a la difusión de los ejemplares que van realizándose en España.

Como se verá en repetidos casos, era imposible introducir en estos espacios cualquier mobiliario al uso, lo cual propició el ingenio de encargar mostradores, lámparas, mesas, estanterías o vitrinas, siguiendo una misma línea, acorde con el concepto estético que se quería hacer público. Sin embargo aún es pronto para considerarlo diseño industrial propiamente, ya que aquí no existía un proceso de fabricación en serie, sino que las piezas eran únicas, eleboradas por artesanos locales.

Lo más interesante de la tienda "Vogue" es la imagen que desde el exterior ofrecía a través de la fachada y puerta de cristal -luna pulida-, que ponía de manifiesto la idea de "escaparate de sí misma" ${ }^{5}$ en el esmeradísimo juego visual entre constructivo y decorativo complementado por el mosaico del suelo de Carlos Pascual de Lara. Otras realizaciones de esta índole fueron en la misma década las tiendas "Lindsay" (1954), "Domus" (de muebles, 1955), "Flomar" (moda, 1957), Heladería "Navarro" (1957), Ortopedia "Alpha" (1954) y ofoconas del Banco Popular (1956). Nuestro conocimiento de ellas se limita a las fotografías por el hecho significativo de haber desaparecido todas. La misma condición de proyectos experimentales, animados por la necesidad de modernidad y originalidad, de romper con el entorno incluso, para llamar la atención de la clientela potencial, implica un continuo proceso de actualización acorde con las tendencias de cada época (aparte de traspasos, cambios de negocio, ampliaciones o quiebras). Esto es lo que les otorga el papel efímero de testimonios de la mentalidad y los gustos de una sociedad en un momento concreto, y quedar las fotografías como valioso documento histórico para la posteridad.

$Y$ ya que me he referido a la fotografía, es el momento de adentrarse en la tienda que falta por citar, "Studio". El fotógrafo José Jiménez Poyato, interesado desde sus comienzos por las artes, puso su primer establecimiento en el bajo de la vivienda del marqués de la Fuensanta del Valle, en la Avenida del Gran Capitán, al lado de la casi mítica cafetería "Dunia". Nuevamente afloró la tendencia a trabajar en equipo, precisamente cuando se gestaba en las

5. Ver DAROCA BRUÑO, F.: Rafael de La-Hoz. Arquitecto. Catálogo de obras y proyectos. Córdoba, 1991, p.19. 
tertulias el "Grupo Espacio" -primer núcleo del "Equipo 57"- formado por Francisco Aguilera Amate, Juan Serrano, José Duarte y Luis Aguilera Bernier, en torno a Jorge Oteiza que se encontraba en Córdoba entre 1953-1954 colaborando con Rafael de La-Hoz. Ya tenemos otra vez en escena a la vanguardia de Córdoba, lo cual nos hace imaginar un intenso ambiente de trabajo en la ejecución de las obras casi simultáneas de la Cámara de Comercio y la tienda "Studio", retrasándose las de esta última por el mismo motivo, ya que el arquitecto las dirigía personalmente y además se fủeron improvisando muchos detalles según los inconvenientes que surgieran.

El aspecto exterior y la estructuración de la fachada se vieron en cierta medida condicionados por la exigencia de instalarla en un muro particularmente masivo ${ }^{6}$, alojando un interior que, a diferencia de los otros ejemplos citados, no era visible desde la calle. El paramento, totalmente plano, se ocultó por un enrejillado vertical en el que se abrieron el escaparate horizontal muy alargado y la puerta, dispuestos de tal manera que la compensación entre horizontal y vertical nos evoca las composiciones neoplasticistas. En paralelo con el escaparate, situado encima de él, quedaría el conducto de ventilación del segundo piso, sólo adivinado por el rectángulo que se trasluce sin alterar la continuidad de la rejilla. La puerta fue, según el propietario, la primera "Securit" que se colocó en Córdoba ${ }^{7}$ y es digno de tenerse en cuenta nuevamente la información que nos proporciona la consulta de la Revista Nacional de Arquitectura al anunciarse estas puertas insistentemente, constituyendo un elemento importante de renovación por ser totalmente diáfanas y resistentes. En "Studio" se convierte en el único punto de transparencia de la fachada hacia la tienda, pero el verdadero protagonismo de los vanos viene señalado por el potente marco saliente que se les puso tanto al escaparate como a la puerta -no quedando ésta difuminada entre lunas, como ocurre en "Vogue" o "Domus"- con el detalle añadido del tirador diseñado por Oteiza. La vitrina sería un punto de reclamo publicitario, cuya función difusora se verá más adelante. En el ángulo superior derecho del muro se coloca el letrero de "Studio", con una gráfica " $\mathrm{S}$ " liquida, todo en caracteres cursivos que describen una diagonal ascendente, rompiendo con el geometrismo austero imperante, iluminadas con cierto "glamour" llamativo y atrayente del gusto de aquellos años.

El interior, tal como nos lo muestra la fotografía conservada, se ofrece como una escenografía de cuidados detalles cuya plasticidad parcial y de conjunto no era casual ni micho menos. Queda patente por la coherencia de los resultados, el interés por dotar a esa imagen de una apariencia fotográfica que responde simbólicamente a la función a la que iba destinado el local. La personalidad del arquitecto se impuso en la zona de ventas cuya forma oval en planta quedaba

6. Aclaración hecha por el propio Rafael de La-Hoz a la autora del artículo en entrevista realizada en Madrid el 25 de abril de 1994.

7. Tomamos este dato con un sentido más anecdótico que veraz, extraído de las descripciones directas que José Jiménez nos proporcionó en 1991. 
reforzada por la escalera curva en el lado derecho y el mostrador, obra de Oteiza de atrevidas trazas, a la izquierda. Detrás de las estanterías que respaldaban a éste, se ocultaban las dependencias del laboratorio, amplias y perfectamente distribuidas en base a dos estancias contiguas cuadrangulares, mientras que el piso alto, ocupado el óvalo por la caja de escalera, contaba con una sola estancia rectangular que se aislaba de ella por medio de persianas de tablillas verticales, como trasunto del esquema de fachada.

Cada una de las piezas que conformaban esa especie de escenografía tenía valor en sí misma y por el papel específico que jugaba dentro del diálogo de formas, texturas y colores que allí se entablaba. La especial atención que Rafael de La-Hoz dedica al empleo de materiales estrictamente seleccionados, si bien se extremó en la tienda "Vogue", aquí no es nada despreciable. El pavimento achinado típico andaluz sin pulir, como si de un jardín se tratase, aporta el sentido textural común a muchas realizaciones de los años cincuenta, al modo de la arquitectura orgánica de Frank Lloyd Wright. Este material en estado natural contrasta con el granito pulido de la escalera, pero sobre todo con el mostrador estilizado terminando en uno de sus extremos en punta, y tallado en madera de pino rojo, que supone también un aporte cromático al conjunto. Rafael de La-Hoz deseaba que los tonos dominantes fueran negros y grises, como en las fotografías, enfrentando la misma silla diseñada por Oteiza mitades blancas y negras. Algunos detalles de color servían para evitar la monotonía: no sólo el mostrador, sino también la falsa lámpara, hecha directamente en el techo a base de cables de colores formando una estrella de múltiples puntas con bombillas en los cruces, de los futuros miembros del "Equipo 57".

Por último se proyectó colocar en una hornacina una talla polícroma barroca de San Rafael, presidiendo la escalera, pero por motivos económicos se optó por la solución "provisional" de poner una fotografía muy ampliada tomada de la cabeza de una de las esculturas clásicas que decoran el patio de los Museos de Bellas Artes y Romero de Torres. Con la iluminación adecuada y el fondo oscuro de la pared, aparece como un efecto de fotomontaje.

Hay que puntualizar que la información que tenemos de la primera sede de "Studio" procede de descripciones parciales y de dos únicas fotografías del interior y exterior respectivamente, que fueron publicadas en el número 154 (Octubre, 1954) de la Revista Nacional de Arquitectura, sirviendo una de ellas de portada y acompañadas de los planos, con la única indicación del nombre del arquitecto. No obstante puede sernos útil establecer un paralelismo entre esta obra y su coetánea la Cámara de Comercio, en cuanto a los materiales empleados y sobre todo a la disposición de los elementos arquitectónicos y compositivos del interior, situándose el mostrador igualmente a la izquierda de la escalera, aunque la curva descrita por ésta en el segundo ejemplo se convierte en caracol conforme se sube más. El 
mostrador también tiene la terminación apuntada, y se debe a Jorge Oteiza, autor además de un mural para la fachada y una escultura en el interior. Una parte del pavimento de la Cámara de Comercio es de chinos, posteriormente pulidos. Incluso el tipo de focos utilizados en ambos casos son semejantes -lámparas cónicas diseñadas por el propio arquitecto- sin olvidar la función de modelado de volúmenes que cumplen siempre en su esmerada disposición.

\section{STUDIO 52}

Antes de entrar de lleno en lo que sería la segunda fase y definitiva de la tienda-galería, voy a detenerme brevemente en ciertos datos sobre su autor, Juan Serrano, que puedan ser útiles. Ya me he referido antes a los orígenes del "Grupo Espacio" que tuvo lugar en Córdoba en un círculo muy próximo al que rodeó la primera sede. Entre 1954 y 1956 se reunieron ciertamente los artistas citados, siguiendo las ideas del ya consagrado escultor Jorge Oteiza. En su breve trayactoria este grupo trabaja conjuntamente en murales, enrejados, decoración en definitiva, con carácter comercial y por encargo. En un viaje a París en compañía de José Duarte, conoce Juan Serrano a Agustín Ibarrola y Ángel Duarte, fundadores todos ellos del "Equipo 57", al que se uniría en Córdoba Juan Cuenca. Olvidado mucho tiempo, ha sido recientemente rescatado este colectivo a través de una exposición en el Centro de Arte Reina Sofía (1993 - Córdoba 1994), reconociéndose por fin la inestimable aportación a la vanguardia que significó, dentro del contexto de grupos coetáneos -"Dau al Set", "El Paso", "Parpalló"- los planteamientos de "interactividad del espacio plástico" que ellos esgrimían en su manifiesto, además de la importancia que tiene el hecho de abandonar sus carreras individuales para actuar en un mismo frente con obras hechas en común. Puesto que las teorizaciones del "Equipo 57", así como su consecuente trayectoria han sido ampliamente estudiadas, no sólo en el catálogo de la exposición, sino ya anteriormente en la monografía del crítico Ángel Luis Pérez Villén, no voy a extenderme en este tema más de lo necesario para seguir el hilo de lo que aquí concierne.

A manera de encuadre amplio diré que toman referencias conceptuales tanto de la Bauhaus, De Stijl y Constructivismo ruso como de Oteiza, con el que luego tendrán discrepancias y acabarán por romper. A finales de 1958 empiezan a trabajar en mobiliario, siendo piezas más artesanales que industriales, para responder a la demanda restringida de una galería. Es un estilo racional que en España resultaba extraño crear, pues se importaban modelos extranjeros, distando aún mucho del desarrollo del diseño nacional posterior. Luego entrarían en contecto con la cooperativa "Danona", que les haría multiplicar la producción. Se le concede especial importancia al diseño industrial por su capacidad de influir en la formación estética de la población. 
Tras la disolución del "Equipo 57", Juan Cuenca, arquitecto, y Juan Serrano, que realizó esta carrera en Madrid titulándose en 1970, ejercen esta profesión colaborando en numerosos proyectos que sitúan a Córdoba en un lugar destacado de la experimentación arquitectónica, conectando las tendencias derivadas del Racionalismo, Organicismo y Estilo Internacional -muy decadente ya a finales de los sesenta y principios de los setenta- con el Postmoderno. Juan Serrano sobresale además por sus proyectos de remodelación urbana en Córdoba, siendo desde 1982 Arquitecto Municipal del Ayuntamiento de su ciudad natal y Arquitecto Jefe de la Oficina del Casco Antiguo, línea en la que ya había trabajado, precisamente cuando construyó "Studio 52" en 1971. En este caso se trata del bajo de un edificio historicista que ocupa la manzana de esquina entre la calle Cruz Conde y Ronda de los Tejares, obra de 1948 de Aurelio Gómez Millán y Carlos Sáenz de Santamaría pensada para viviendas, cuya entrada se sitúa en el lateral de la Ronda de los Tejares. Así, el acceso de la esquina, zona del edificio que explota las posibilidades de la perspectiva, queda reservado a la tienda, por lo que Juan Serrano en su intervención se vio obligado a adaptar su proyecto a elementos inviolables como son las dos columnas. Estas se convierten poco más o menos en protagonistas, centro de la composición que se desarrolla en torno a ellas, rompiendo y enfatizando la entrada a un mismo tiempo. No cabe duda de que resultaría chocante a principios de los años setenta, pero desde nuestra óptica actual podemos perfectamente asimilarlo, ya la que la simbiosis es uno de los recursos más frecuentes de la llamada arquitectura postmoderna.

El valor está en haber resuelto la esquina con un dinámico juego de curvas y aristas simétricas que hacen posible el respeto a lo ya existente sin renunciar por ello a la originalidad y a la renovación, sugieriéndose la referencia a un "orden gigante" que abarca dos pisos. Se comunican convexidades y concavidades y esa inflexión hace que el espacio continente se convierta en contenido y viceversa.

La composición de la fachada se ve además definida por elementos que no son puramente constructivos, como son el enrejado de la entreplanta y los escaparates del piso inferior. Estos últimos combinan los ángulos rectos con las curvas, empleando así un lenguaje parejo al de la estructura general, y que además vuelve a repetirse en el mobiliario interior (mostradores, estanterías y vitrinas).

Una pieza interesante es la escalera de caracol que comunica con la sala de exposiciones. Más que cumplir la función que le es propia, se nos ofrece como una escultura en conexión con el diseño industrial, o más bien artesanal, del "Equipo 57". Es una prototípica interrelación de las formas lineales racionalistas con las incursiones orgánicas del Estilo Internacional. A través de ella se llega a la entreplanta que sirve de almacén a la tienda, y al piso superior donde, además de la sala de exposiciones, se encuentran las oficinas, el estudio fotográfico y gran 
parte de la colección de cuadros que posee José Jiménez Poyato, aunque el acceso más habitual es la portería y escalera del bloque primitivo.

La sala de exposiciones es de dimensiones bastante reducidas, con clara tendencia al alargamiento. Cuenta con un mobiliario básico que sirve para celebrar tertulias: mesa y butacas circulares pequeñas de diseño al gusto de los años setenta, lo mismo que la lámpara de forma globular que pende de un brazo arqueado. Así se continúa con la relación entre líneas rectas y curvas. El sentido longitudinal de la sala es paralelo al exterior, es decir, de los dos lados mayores uno es muro y el otro vano, con lo que la mitad de los cuadros cuelgan sobre un fondo de cortina, recibiendo la luz desde atrás. Esto significa que las exposiciones deben ser visitadas preferentemente al sol puesto.

$\mathrm{El}$ enrejado que antes he citado rodea todo el piso intermedio de la tiendagalería, resultando ser una evocación de la fachada antigua de "Studio", convirtiéndose en un elemento unificador de ambas. Como lo es igualmente la estética de lo transparente, más conseguida en esta segunda versión en la que se logra una total comunicación del interior con la calle. Un detalle curioso en este sentido es la recuperación de aquella misma puerta "Securit", a la que se le ha puesto un muelle y sigue resistiendo.

También aquí contamos con dos factores decisivos en la apreciación final del conjunto: la elección de los materiales, como en la obra de Rafael de La$\mathrm{Hoz}$, persiguiendo la creación de contrastes entre las zonas lisas pintadas de blanco y la reja oscura, añadiendo el acero -un material nuevo y muy usado en esa década tanto en arquitectura como en escultura- en el hueco circular de la escalera, con la referencia orgánica de la vegetación. Volvemos a interpretarlo como el emblema de un establecimiento fotográfico, por la dialéctica entre positivos y negativos expresada a través de los propios volúmenes y reforzada por la disposición intencionada y esmerada de los focos y lámparas, tanto en el interior como en el exterior.

Los orígenes de lo que hoy es galería se fundamentan en el uso que le dio José Jiménez al escaparate de su primera tienda, en el que exponía cuadros y sus propias fotografías, una iniciativa novedosa, máxime si se tiene en cuenta la temática de sus imágenes populares, que casi se podrían decir conectadas con el arte de denuncia social. Diecinueve años estuvo la tienda "Studio" en funcionamiento en su local de la Avenida del Gran Capitán, para trasladarse luego, con el nombre de "Studio Jiménez" al lugar que hoy ocupa, con la galería "Studio 52" arriba, haciendo un homenaje a la fecha de su fundación. Es indiscutible la inquietud constante de este fotógrafo por ser el promotor de algo más que un comercio. Desde un principio, y aunque hasta 1971 no tuvo sala de exposiciones, se mueve dentro del círculo cultural de las tertulias que se celebraban en la cafetería "Dunia". Se supo rodear de artistas y poetas, teniendo amistad con los 
componentes del grupo "Cántico", al tiempo que él mismo desarrollaba su actividad creativa. Esta faceta se refleja en los detalles con que trata el acabado de sus tiendas, perfectos modelos fotográficos concebidos con una intención de crear ambiente. Ininterrumpidamente desde su inauguración, ha acogido esta galería infinidad de muestras a lo largo de más de veinte años, convirtiéndose e uno de los más activos centros expositivos de Córdoba. No olvidemos la mala fortuna que ha acompañado a las galerías privadas de esta capital, cuya vida ha sido relativamente corta. Sin intención de ser exhaustiva, no voy a enumerar todos los escultores y pintores que han pasado por la pequeña sala, como han sido entre otros Rafael Botí, Antonio Bujalance, Pedro Bueno, Rafael Orti, Juan Polo, Antonio Povedano, etc., dominando la presencia de artistas cordobeses a quienes se ha contribuido a promocionar. 


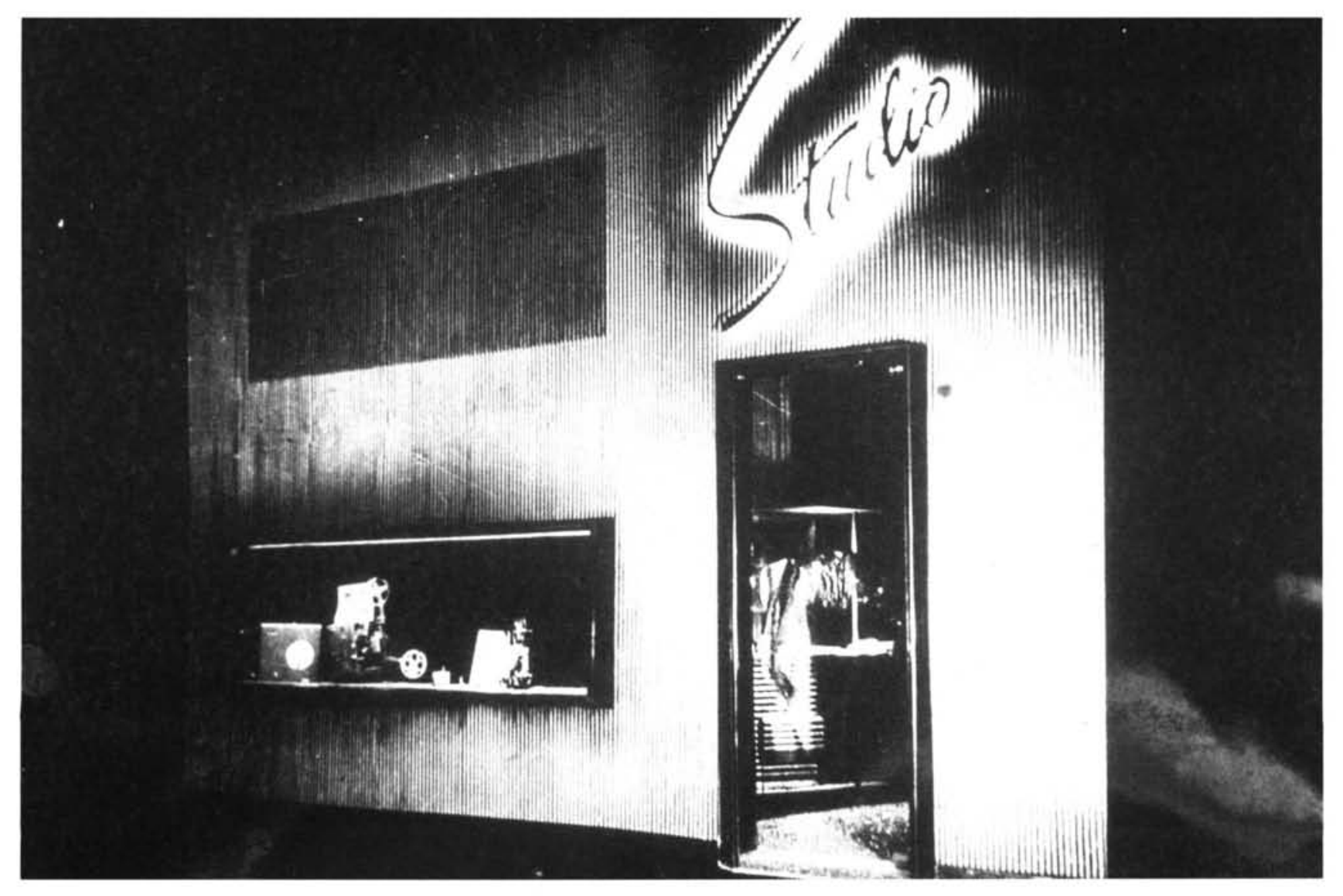

Foto 1: Primer establecimiento "Studio". Rafael de La-Hoz. 


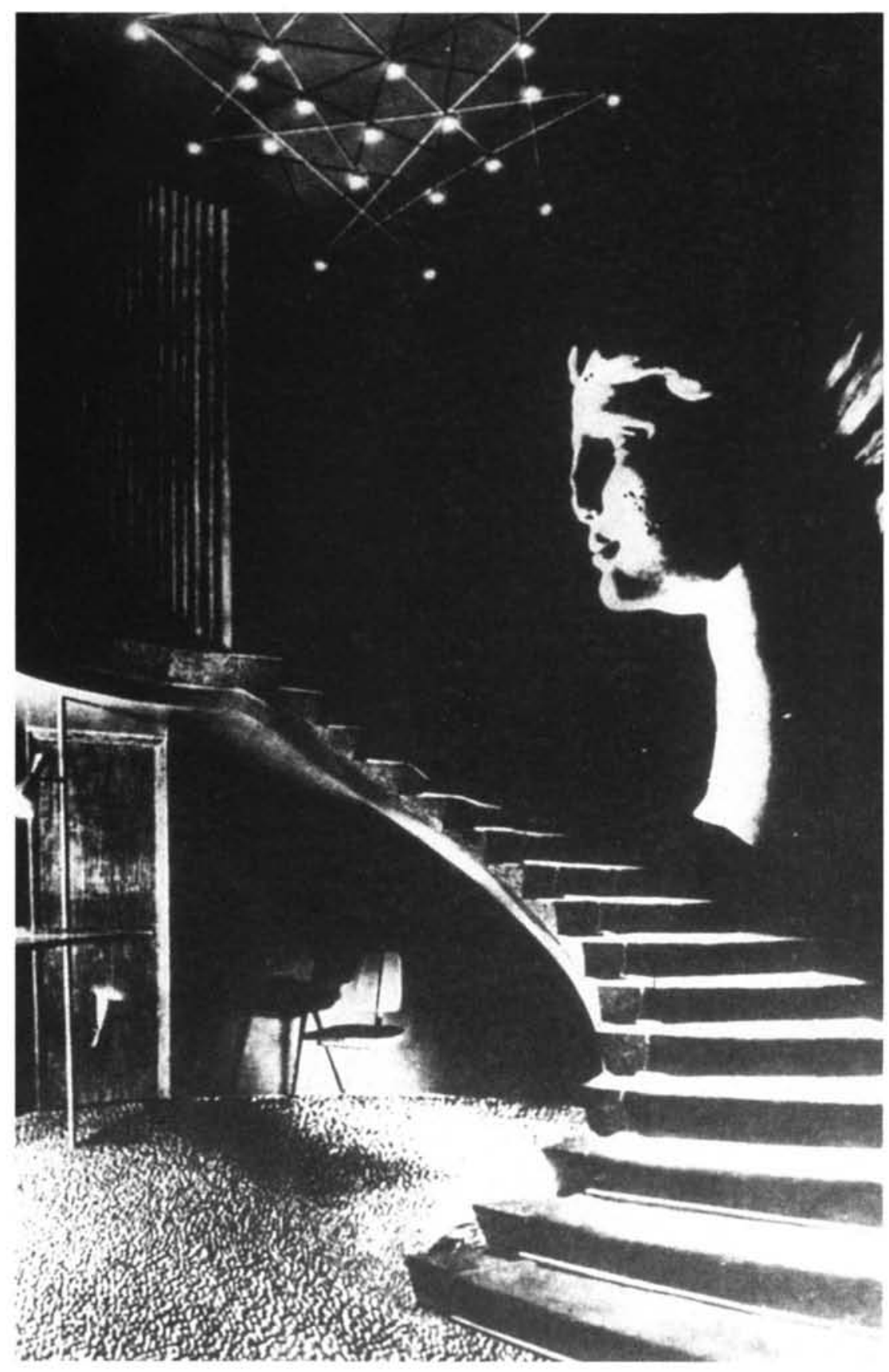

Foto 2: "Studio". Interior 


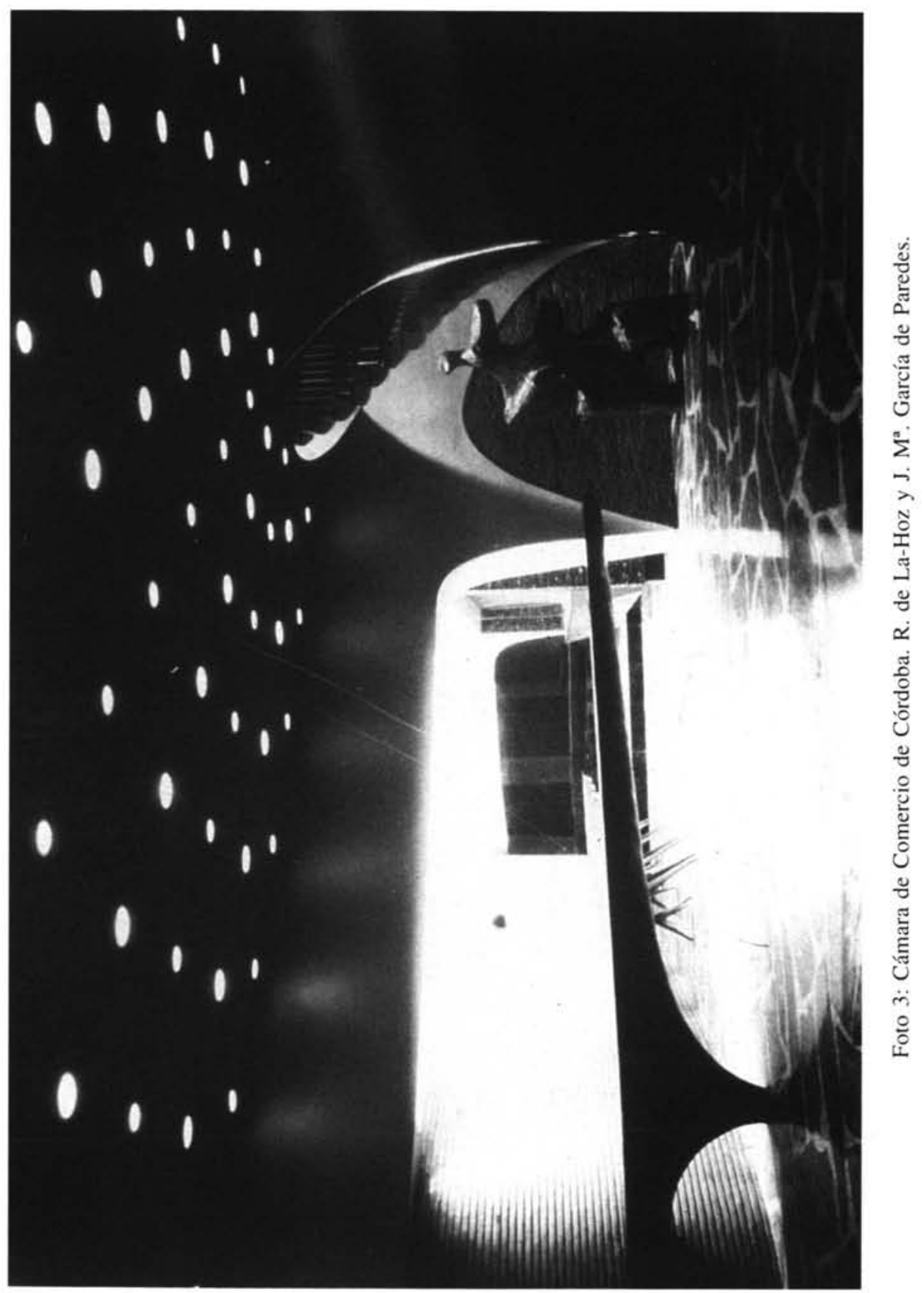




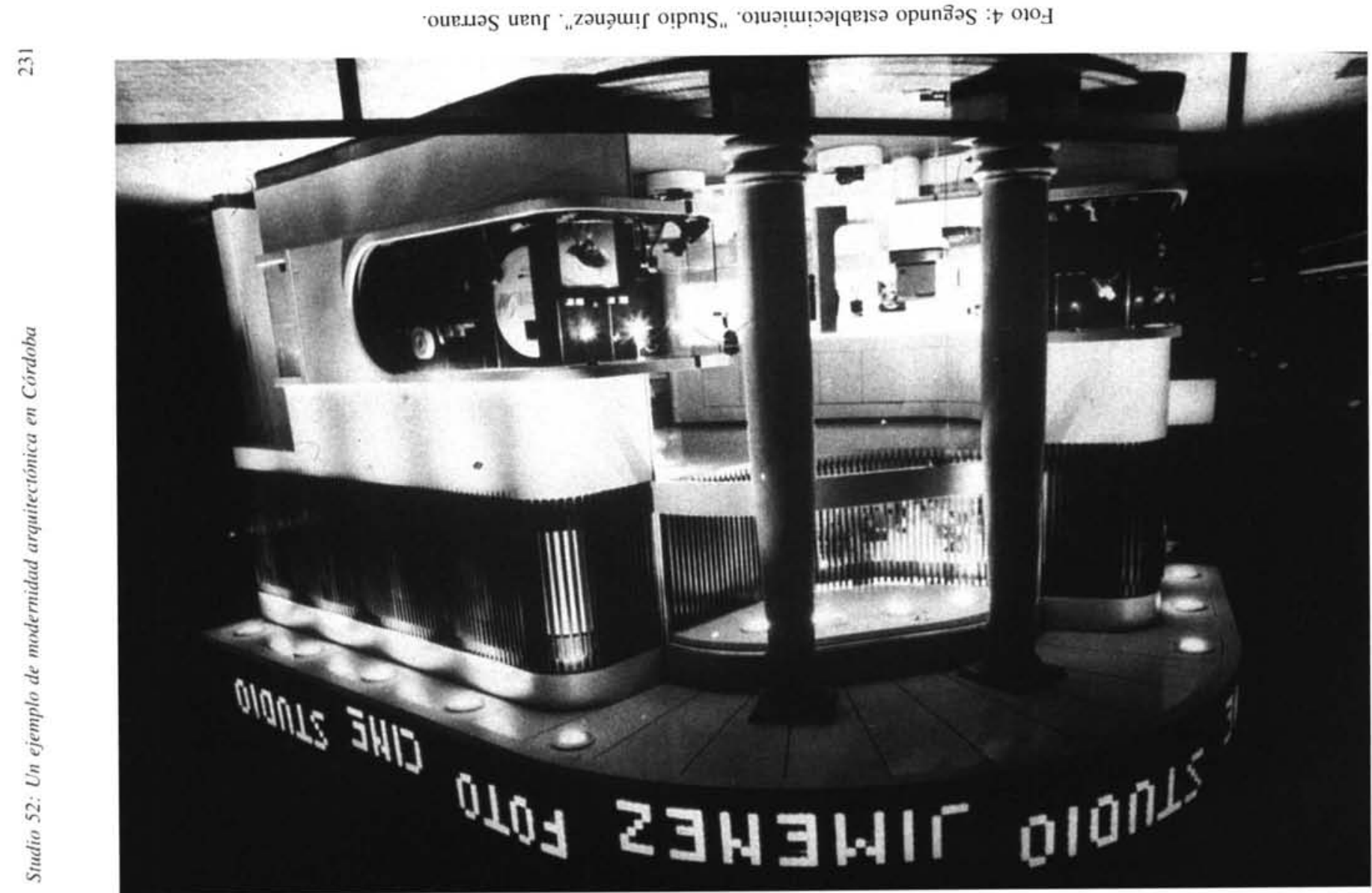




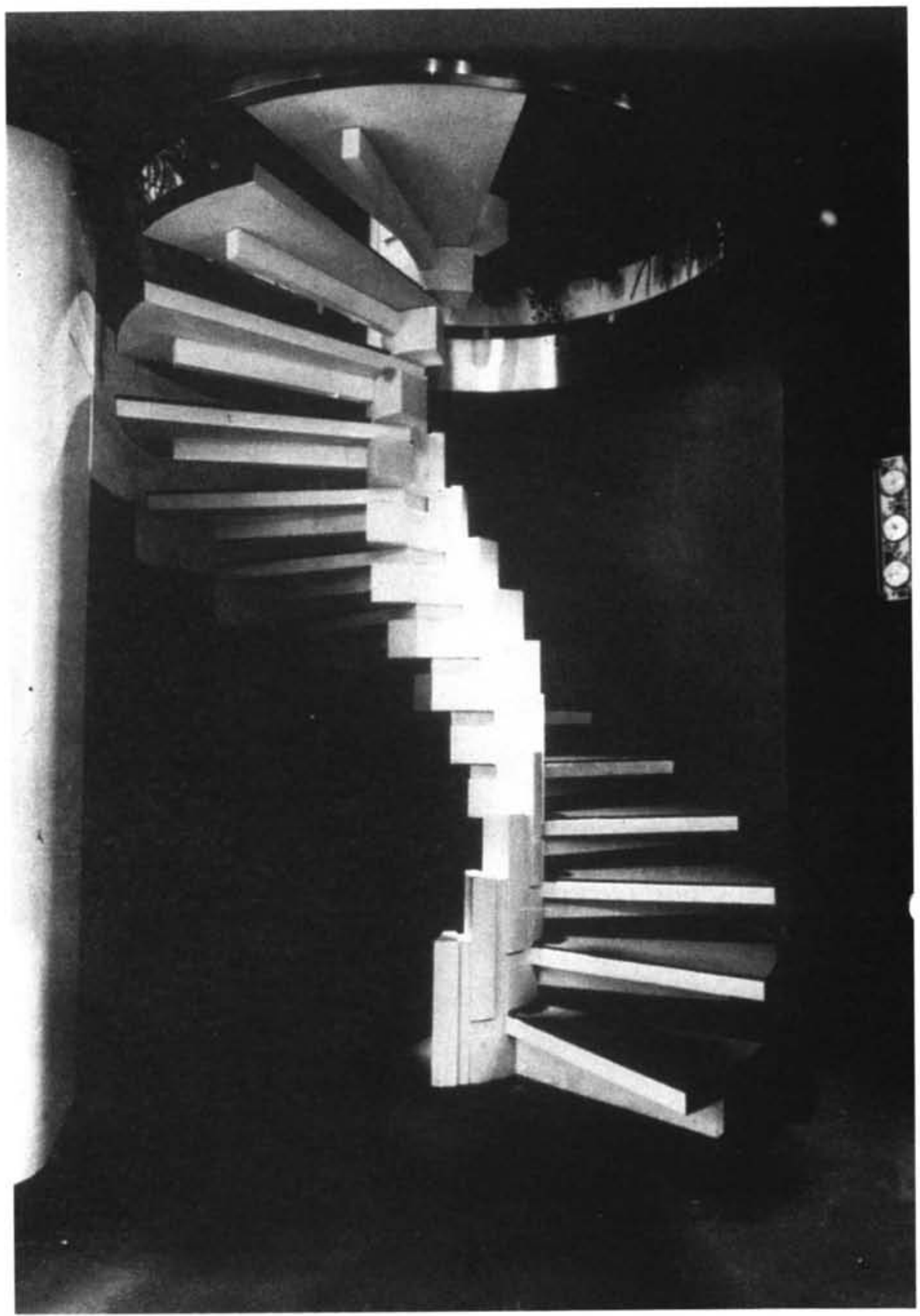

Foto 5: Detalle de la escalera de "Studio Jiménez". 


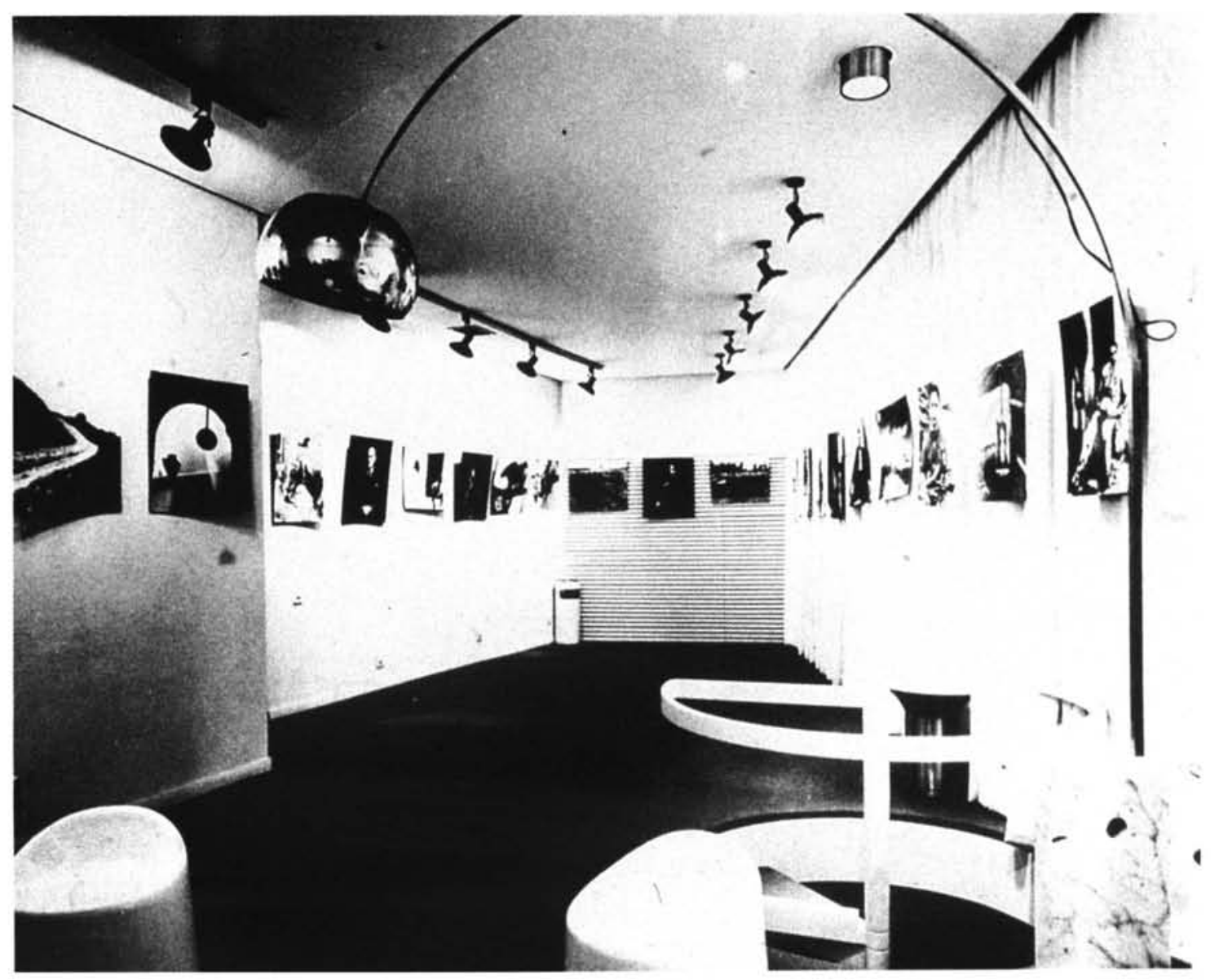

Foto 6: Galería de Arte "Studio 52" (planta superior de "Studio Jiménez"). 